\title{
Funding for accelerating drug development initiative critical
}

FDA's Critical Path Initiative needs industry resources to succeed

\section{Joanna Owens}

The announcement of the next stage of an ambitious plan from the FDA for speeding up the process of bringing beneficial medicines to patients has been met with great enthusiasm by all parties in the field. But pioneers of the initiative are worried that if this enthusiasm cannot be met with industry funding, the opportunity to tackle these burning issues could be wasted.

\section{The industry cannot} depend on the FDA to do this research because funds are simply not available.

Last month, the FDA announced a list of 76 'opportunities', or projects, for developing new tools that could significantly improve the way that experimental drugs are tested.

The opportunities cover six broad topic areas: development of biomarkers; clinical trial designs; bioinformatics; manufacturing; public health needs; and paediatrics.

The announcement is the latest part of an ongoing FDA initiative, called the Critical Path. Two years ago, the FDA released a white paper giving its diagnosis on why there has been a dearth of new drugs approved in recent years, despite firms pouring more and more money into developing treatments. The white paper's damning conclusion was that the tests used to develop new medical products are decades old, and are costly and inefficient.

Identifying the 76 opportunities for improving drug development required a great effort; but even more will be needed to successfully address them. This is something that the FDA cannot accomplish by itself, warns Janet Woodcock, Chief Operations Officer at the FDA, and one of the main driving forces behind the initiative.

Success will require unique collaborations between academic, government and industry researchers. "The Critical Path Initiative could be transformative, but it's also very fragile," says Woodcock. "It's going to need real commitment across a number of sectors to get going."
Funding is a big issue. For instance, the institute set up specifically to facilitate the FDA's Critical Path Initiative is concerned as to where funding will come from to carry out the necessary research.

The Critical Path Institute (known as C-Path), based in Tucson, Arizona, is a nonprofit group created to act as a "neutral ground' for scientists from the FDA, industry and academia. At $\mathrm{C}$-Path, researchers can get together to identify and validate the new tools and technologies needed to help accelerate drug development. C-Path is currently funded to the tune of US\$11 million, with contributions from the State of Arizona, the City of Tucson, Pima County, regional municipalities, foundations, organizations and private individuals.

Four projects are underway (see BOX 1), but will take years of research and validation to complete. Existing funding will only enable C-Path to seed the projects, admits C-Path President, Ray Woosley. "The industry cannot depend on the FDA to do this research because funds are simply not available," he says. "Process improvement is not an item in the FDA's budget."

Woodcock believes that most large companies are beginning to recognize that changing their existing R\&D models could be their best chance of modernizing the drug development process.

"[Companies have] been investing a lot of money in their own silos and it's not paying off," says Woodcock. "So it comes down to a business decision about return on

\section{Box 1 |Faster, safer, smarter drugs}

The Critical Path Institute intends to oversee three main initiatives - Fast-Path, SafePath and Ed-Path - each comprising two or three collaborative programmes, such as the Predictive Safety Testing Consortium. So far only four small projects have started, with insufficient funding to complete them: - Cardiovascular Genomics Project - Orphan Disease Registries - Toxicogenomic Cross-Validation Consortium - Arizona-wide Community Pharmacy Network Source: The C-Path Institute: http://www. c-path.org investment." For instance, if industry is going to invest in biomarkers anyway, companies would surely want to invest in something that is going to deliver.

Some companies agree. For instance, C-Path has just announced the formation of the Predictive Safety Testing Consortium. Eight pharmaceutical companies - BristolMyers Squibb, GlaxoSmithKline, Johnson \& Johnson, Merck, Novartis, Pfizer, Roche and Schering Plough - will share internally developed laboratory methods to predict the safety of new treatments before they are tested in humans.

Pfizer says it joined the Predictive Safety Testing Consortium because "the ability of one company or lab to bring potential markers all the way to validation is limited," says Denise Robinson-Gravatt, Director of Research Technology for Worldwide Safety Sciences at Pfizer.

Novartis is also enthusiastic about the consortium. But Paul Herrling, Head of Corporate Research at Novartis, hopes that companies can be seen to fund C-Path without compromising 'safe harbour' or jeopardizing the integrity of the research.

\section{Many in the industry may} say that joint efforts are a good idea in principle, but there is little evidence that firms are willing to seriously fund them.

"We already have fees we pay that enable the FDA to hire personnel, and there is a limit because the FDA cannot be seen to be dependent on the industry and to be influenced by it," says Herrling. "There is already a bad perception of the industry

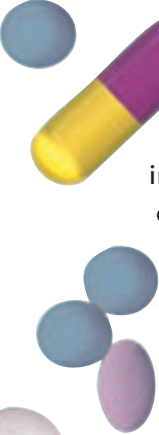
in that sense."

The fact remains that many in the industry may say that joint efforts are a good idea in principle, but there is little evidence that firms are willing to seriously fund them.

A request for $\$ 5.9$ million has been put forward in the President's budget for this year for the FDA to devote to C-Path, which, as Woodcock admits, "is

not research funding, but it's a start."

Given that any company with a blockbuster drug makes around $\$ 6$ million in less than a week, matching the FDA's funding - at the very least - seems a small price to pay for improving drug development's future. 